\title{
NASA's Radioisotope Power Systems - Plans
}

John A. Hamley ${ }^{1}$, Peter W. McCallum ${ }^{2}$, Carl E. Sandifer $\mathrm{II}^{3}$, Thomas J. Sutliff ${ }^{4}$, and June F. Zakrajsek ${ }^{5}$ NASA Glenn Research Center, Cleveland, $\mathrm{OH} 44135$

NASA's Radioisotope Power Systems (RPS) Program continues to plan and implement content to enable planetary exploration where such systems could be needed, and to prepare more advanced RPS technology for possible infusion into future power systems. The 2014-2015 period saw significant changes, and strong progress. Achievements of near-term objectives have enabled definition of a clear path forward in which payoffs from research investments and other sustaining efforts can be applied. The future implementation path is expected to yield a higherperforming thermoelectric generator design, a more isotope-fuel efficient system concept design, and a robust RPS infrastructure maintained effectively within both NASA and the Department of Energy. This paper describes recent work with an eye towards the future plans that result from these achievements.

$\begin{array}{ll} & \\ \text { ASC } & =\text { Advance Stirling Convertor } \\ \text { ASRG } & =\text { Advance Stirling Radioisotope Generator } \\ \text { ATEC } & =\text { Advanced Thermoelectric Convertor devices } \\ \text { ATOM } & =\text { Advanced Thermoelectric Materials } \\ \text { BOM } & =\text { Beginning of Mission } \\ \text { CBCF } & =\text { Carbon Bonded Carbon Fiber } \\ \text { DOE } & =\text { Department of Energy } \\ \text { DRM } & =\text { Design Reference Mission } \\ \text { DRS } & =\text { Design Reference System } \\ \text { EC } & =\text { Executive Council } \\ \text { eMMRTG } & =\text { Enhanced MMRTG } \\ \text { EU2 } & =\text { Engineering Unit 2 (ASRG) } \\ \text { F2, F3 } & =\text { Flight Unit 2 \& 3 (MMRTG) } \\ \text { FPS } & =\text { Fission Power System } \\ \text { FWPF } & =\text { Fine Weave Pierced Fabric } \\ \text { FY } & =\text { Fiscal Year } \\ \text { GPHS } & =\text { General Purpose Heat Source } \\ \text { GRC } & =\text { Glenn Research Center } \\ \text { HEOMD } & =\text { Human Exploration and Operations Mission Directorate } \\ \text { INL } & =\text { Idaho National Laboratory } \\ \text { INSRP } & =\text { Interagency Nuclear Safety Review Panel } \\ \text { JPL } & =\text { Jet Propulsion Laboratory } \\ \text { LANL } & =\text { Los Alamos National Laboratory } \\ \text { LM } & =\text { Lockheed Martin } \\ \text { LWRHU } & =\text { Light-Weight Radioisotope Heater Unit } \\ \text { MMLAE } & =\text { Multi-Mission Launch Approval Engineering } \\ \text { MMRTG } & =\text { Multi-Mission Radioisotope Thermoelectric Generator } \\ \text { MSL } & =\text { Mars Science Laboratory } \\ & \end{array}$

${ }^{1}$ Program Manager, RPS Program Office, 21000 Brookpark Road, MS 162-6, AIAA Senior Member

2 Program Control Manager, RPS Program Office, 21000 Brookpark Road, MS 162-6

${ }^{3}$ DOE Operations and Assessment Manager, RPS Program Office, 21000 Brookpark Road, MS 162-6

${ }_{5}^{4}$ Deputy Program Manager, RPS Program Office, 21000 Brookpark Road, MS 162-6

${ }^{5}$ Program Planning and Assessment Manager, RPS Program Office, 21000 Brookpark Road, MS 162-6 


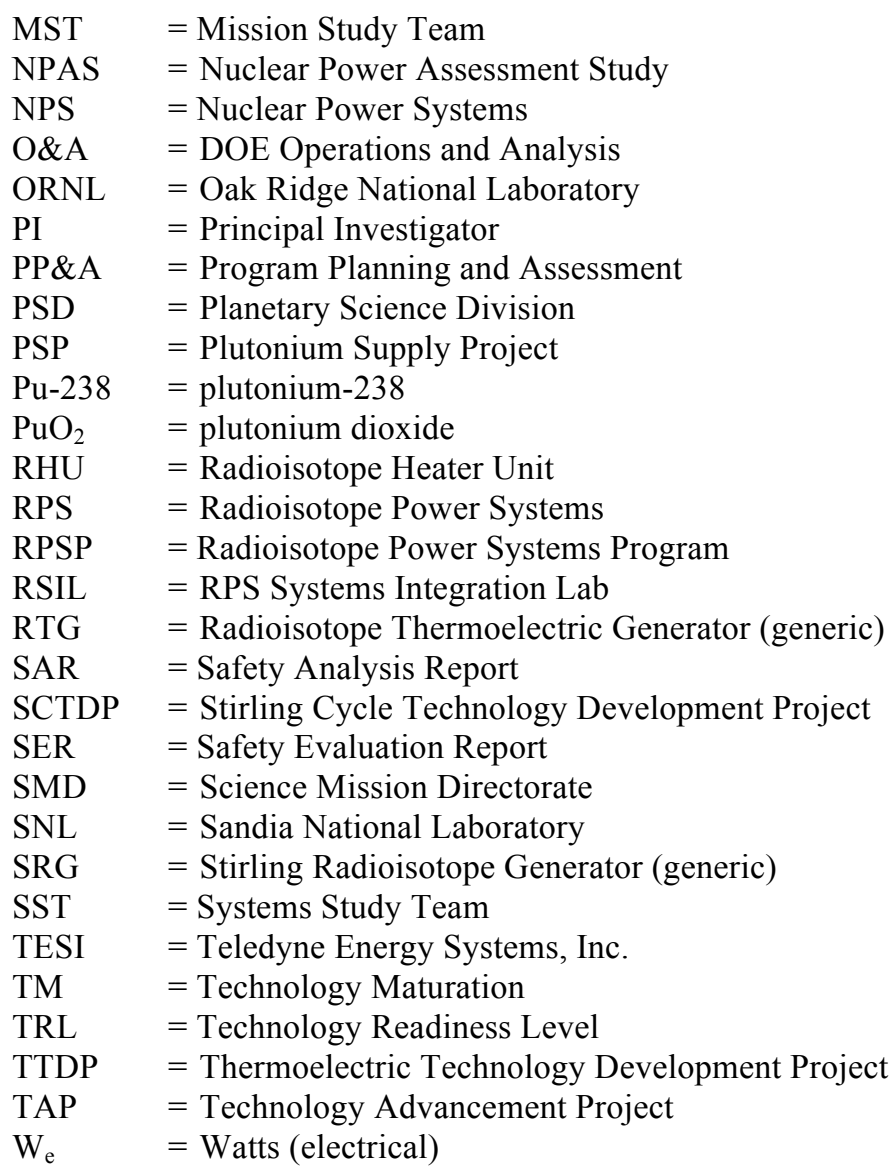

\section{Introduction}

NASA's Radioisotope Power Systems (RPS) Program exists to provide solutions for the deep space power needs of U.S. robotic planetary science spacecraft. The RPS Program's goal is to make RPS available for the exploration of the solar system in environments where conventional solar or chemical power generation is impractical or impossible to use to meet mission needs. To meet this goal, the RPS Program manages investments in RPS system development and RPS technologies.

Significant progress and some fundamental changes to the content within the RPS Program occurred in 2014-2015. The Program content consists of flight system development and capabilities sustainment, as well as research and development activities for advanced energy conversion system technologies. The RPS Program also invests in advancing multi-mission data products in an area known as Launch Approval Engineering, to enable efficient mission implementation once NASA identifies a specific mission with a potential need for RPS.

Furthermore, the RPS Program provides NASA management insight to maintain the core capabilities at the Department of Energy (DOE) needed for space nuclear power system deployment. These capabilities include the re-establishment of a production capability for the RPS heat source isotope, Pu-238, as well as the operations and analysis capabilities to process and certify the $\mathrm{Pu}-238$ heat source as ready for flight use in an RPS.

Finally, the RPS Program conducts studies of future mission and systems that would benefit from use of RPS, and assesses their potential required capabilities. This past year, the RPS Program conducted a comprehensive Nuclear Power Assessment Study (NPAS) to consider options for needed technology investments in RPS and potential fission-based power systems, as well as other investment considerations.

\section{Systems}

Flight system development activities during the past year have focused on three areas: maintenance of the ability to deploy either or both of the previously constructed Multi-Mission Radioisotope 
Thermoelectric Generators (MMRTGs) for mission-specific purposes; transition planning for the potential on-ramp of improved thermoelectric conversion technology for an enhanced MMRTG; and, the replanning of a development strategy for Stirling energy conversion technologies resulting from the 2013 cancellation of the Advanced Stirling Radioisotope Generator (ASRG) flight project.

The RPS Program has a Level I requirement to ensure the availability of RPS for missions requiring nuclear power for implementation. Currently, the MMRTG is the only flight qualified RPS available for this purpose. A total of three flight MMRTGs were constructed. The first is providing dependable electric power and heat for the Curiosity Mars rover mission, which launched in 2011 and is currently exploring the Gale Crater and Mount Sharp on Mars. Figure 1 shows this MMRTG attached to the rear of Curiosity on the surface of Mars. The program funded the completion of two additional MMRTG flight units, known as F2 and F3 up to the point of fueling, final assembly, and testing. These units, built in part to sustain thermoelectric fabrication capability, were placed in bonded storage awaiting assignment to a flight mission. One of the two will be baselined for use on the Mars 2020 mission.

Construction of the thermocouples that convert the heat of decay of plutonium-238 into electricity is a critical technology that must be sustained to ensure availability of MMRTGs for future missions. The thermoelectric devices constructed for this purpose are unique items that do not have a commercial market base that facilitates their on-going fabrication. In order to maintain this capability, the RPS program funds a sustainment activity wherein these thermocouples are fabricated to put on test, in storage, or be integrated into a flight-capable system for future mission integration. The quantities produced strike a balance between maintaining the capability without creating a hardware surplus.

This sustainment activity resulted in production of the F2 and F3 flight units and the availability of an off-the-shelf MMRTG for the planned Mars 2020 rover mission. As baselined, this rover will closely resemble the Curiosity rover, making the future mechanical integration of this device straightforward. The RPS Program is working closely with the Mars 2020 mission team to facilitate the final production and delivery of the flight unit by the DOE. The DOE in concert with the mission will select the generator for fueling, then complete the final assembly and test, and deliver the device for integration onto the spacecraft. One flight unit will remain unfueled and would be available for the next mission requiring use of an RPS for power.

The RPS Program must also sustain the technology base within the agency for power conversion. The agency is committed to

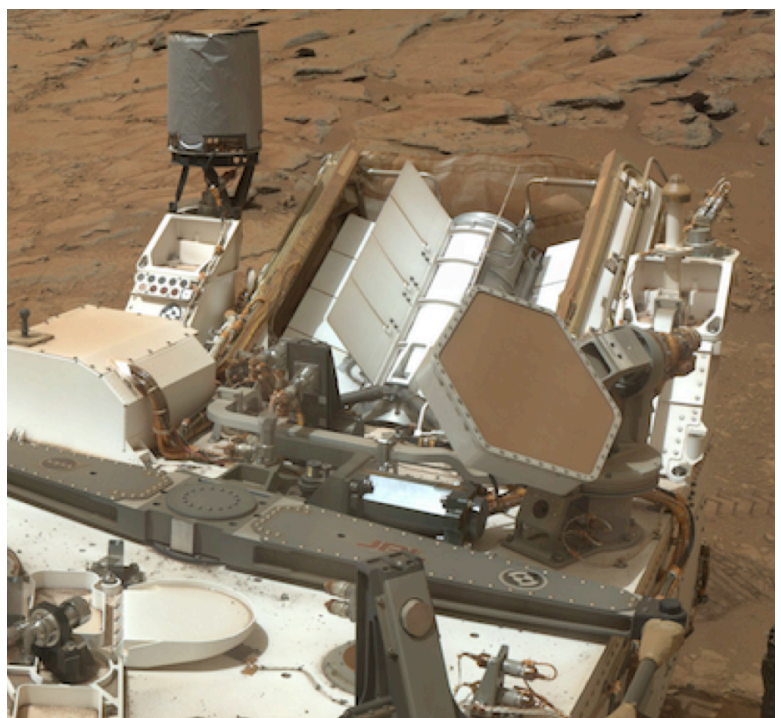

Figure 1. MMRTG on the Curiosity rover; after arrival on Mars in August 2012.

maintaining a cadre of expert technologists in the areas of static and dynamic power conversion technologies to support the application of these devices to future missions. Some of these resources are allocated to low-maturity technologies that target performance improvements with the eventual goal of flight hardware implementation.

Thermoelectric research, described in more detail below, is on going at the NASA Jet Propulsion Laboratory (JPL) on basic materials and device fabrication. Recent developments in Skutterudite materials have advanced this technology to the point of being a candidate for transition to flight systems. A technology maturation effort is currently underway to develop an enhanced MMRTG (eMMRTG) whereby JPL technologists are working with Teledyne Energy Systems, Inc. (TESI) to integrate these new thermocouples into an MMRTG housing. If successful, the net result will be a device with performance improvements in beginning of life power due to higher efficiency, but also significantly better end-ofmission $(\mathrm{EOM})$ power output due to reduced device degradation. The program has scheduled decision gates by which to monitor this process to gauge progress and determine whether or not to proceed to flight-ready status. 
This technology maturation process provides the program a key advantage in that a single investment both sustains the in-house technology efforts and the industrial vendor that produces the flight hardware. Further, the risk is reduced considerably by the direct involvement of the technologists responsible for a given product with the industrial source.

The ASRG project was cancelled in 2013 due to NASA Planetary Science budget issues. The flight converters were being fabricated, the flight generator housings were in hand, and the controller hardware was ready for production. With the termination of the ASRG flight hardware contract, all work on flight hardware was immediately halted. The assets associated with the contract had to be redistributed to government facilities or scrapped. The RPS Program took custody of these assets and distributed them strategically in the best interests of the federal government. Upon termination of the contract and redistribution of the assets, the DOE decertified the hardware produced for flight due to the end of quality and mission assurance surveillance.

Some of this hardware was delivered to NASA Glenn Research Center (GRC) and was integrated into a system, referred to as Engineering Unit 2 (EU2). The EU2 mated a pair of the third-generation Sunpower Advanced Stirling Convertors (ASC-E3) in an aluminum housing in a flight-like configuration. A brassboard controller fabricated by the original flight system integrator and electric heating elements completed the EU2 assembly.

The EU2 was successfully operated as a system and its performance was characterized. The system operated as expected, but testing was eventually halted due to output power fluctuations in one of the ASCE3 converters. The cause of the power fluctuation is being investigated. The system did demonstrate successful startup and operation and detailed results of the testing are detailed in Ref. 1.

NASA's Planetary Science Division (PSD) decided to sustain a level of Stirling technical support at GRC and converter manufacturing at Sunpower as a part of the RPS program's baseline. High-efficiency Stirling power generation remains a critical technology for the future of Solar System exploration, and is enabling to missions where the MMRTG or eMMRTG may not meet requirements. In addition, Stirling systems would extend the utility of the nation's limited supply of plutonium dioxide fuel for RPS.

The program is currently considering development of a new Stirling Radioisotope Generator (SRG) system for potential flight opportunities in the next decade. Plans are being made with the DOE to assess the state of the art in dynamic power conversion and to develop the requirements for a generator in the 100$300 \mathrm{~W}$ output class. Following development of the requirements set, a technology maturation effort modeled after the current eMMRTG project would develop the system to the qualification unit level. Following this, flight hardware would be fabricated. The technology maturation phase would begin in FY16.

Other radioisotope power systems continue to support planetary exploration. The two Voyager spacecraft continue to return valuable scientific data after more than 35 years of space operations- with Voyager 1 having left the Solar System for interstellar space - thanks to the durable capabilities of their Multi-Hundred Watt RTGs. The Cassini spacecraft has achieved over 10 years of orbital science operation at Saturn powered by three General Purpose Heat Source RTGs (GPHS-RTGs). In July, 2015, the New Horizons spacecraft flew by Pluto nine years after its launch, capturing the closest approach images and transmitting data back from this mission using power from a single GPHS-RTG.

\section{Technology Investments}

The RPS Program has changed its approach to managing its technology investments. The previous Technology Advancement Project (TAP), which encompassed all technologies being managed within the program, was bifurcated into its two remaining elements. These two projects have been formed to increase individual focus on each project and aid their successful implementation. The Thermoelectric Technology Development Project (TTDP) and the Stirling Cycle Technology Development Projects (SCTDP) were formulated and formally allocated to their performing organizations.

Budgetary limitations in PSD have reduced the research and development resources available for low Technology Readiness Level (TRL) technologies. At the inception of the RPS program in 2009, a technology portfolio that encompassed thermoelectrics, thermophotovoltaics, and free-piston and thermoacoustic Stirling energy conversions was inherited and managed under a single TAP. With the progression of time and demands on the program, the need for a more focused portfolio emerged. Resource availability drove the program to emphasize technologies with strong "mission pull" and a higher TRL to facilitate more expedient transfers to flight readiness. As a result, work on thermophotovoltaics and 
thermoacoustic Stirling technologies was halted and the resources transferred to thermoelectrics and freepiston Stirling technologies.

The TTDP and SCTDP projects are managed by JPL and GRC, respectively. Each project tracks and reports their resources and progress at regular intervals to the RPS Program. They benefit from better synergy within their locus of technology within each performing organization.

\section{A. Thermoelectric Technology Development Project}

The TTDP is formulated into three distinctive tasks, Advanced Thermoelectric Materials (ATOM), Advanced Thermoelectric Devices (ATEC), and Technology Maturation (TM). These three tasks are scoped for full life cycle development of a given technology. The technology flow and decision gates for these tasks are illustrated in Figure 2 and further described in Ref. 2.

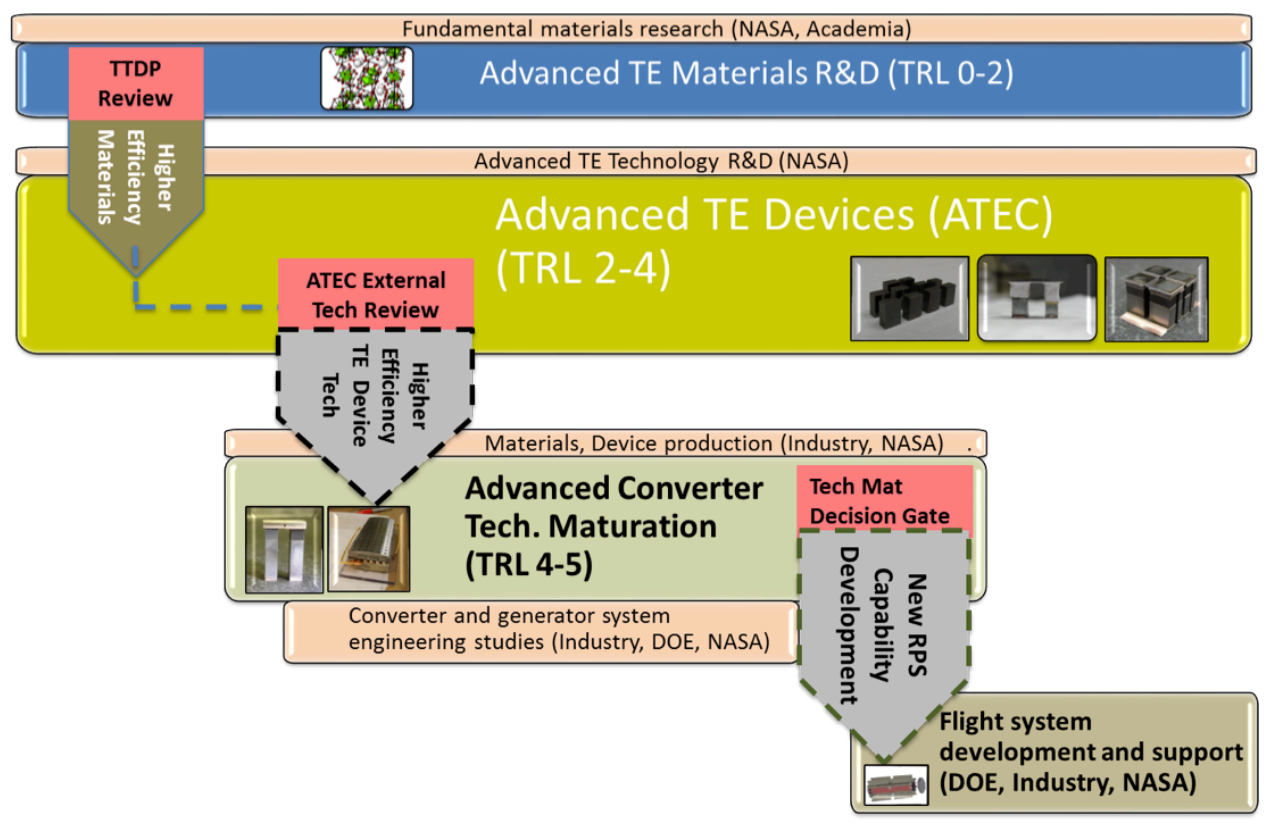

Figure 2. Workflow in the RPS Thermoelectric Technology Development Project.

The ATOM task investigates new thermoelectric materials for performance and manufacturability into a flight-like thermocouple. Initial performance parameter predictions are made, and the materials are fabricated and characterized via test protocols. Specific material performance goals have been established. A long-range goal includes development of a next-generation couple having an efficiency of greater than $18 \%$, nearly three times better than the MMRTG.

The ATOM task is currently working on materials for segmented thermocouples, which utilize Rare Earth, Skutterudites, and Zintls. These devices are segmented to take best advantage of their properties at a

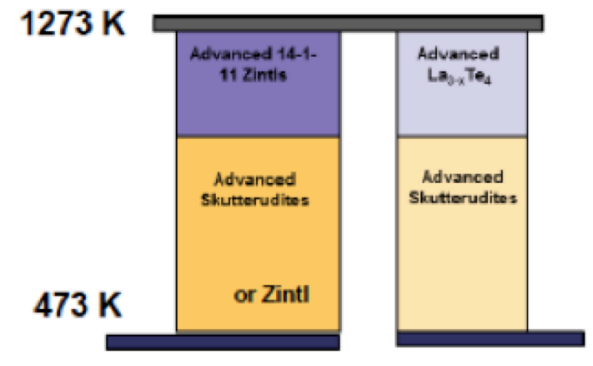

Figure 3. Segmented thermocouple utilizing advanced materials. given temperature, leveraging the temperature gradient over the length of the couple. This "next generation" couple is illustrated in Figure 3.

In addition to the basic materials work, ATOM also investigates materials issues related to the metallization and bonding of the semiconductor material for electrical contacts. The high temperatures at which these devices operate can drive sublimation of the semiconductors to occur, resulting in a loss of mass from the thermocouple. This results in a performance loss over time, and can result in the plating of this sublimated material on cooler surfaces within the generator. Anti-sublimation coatings 
are being developed to mitigate this process. These coatings must survive the high temperature of operation and not react chemically with the devices that they are protecting.

The ATEC task further develops the most promising materials identified by the ATOM task into flightlike devices and modules as candidates for infusion into flight designs. The task investigates and resolves issues concerning materials strength and stability, develops fabrication processes and procedures, fully characterizes device degradation over time, and evaluates possible performance improvements.

Like the ATOM task, ATEC has established performance criteria and deliverables for the objective evaluation of the devices to determine their suitability for eventual integration into flight hardware. These criteria are accompanied by set standards for accelerated life tests and other tests, with clear success definitions that are designed to extensively characterize the materials and devices and inform any decision to proceed to flight. Tests are performed on single devices and modules to develop an extensive performance database for the configurations planned. ${ }^{3}$

Skutterudite-based couples are currently the most mature devices developed under ATEC. JPL and TESI are currently jointly developing them jointly for integration into the current MMRTG housing under the TM task. This development model, illustrated in Figure 4, allows for the direct interaction of the technologists who developed the couples with the flight hardware vendor. The combination of these advanced couples into an MMRTG design is being designated the enhanced MMRTG (eMMRTG).

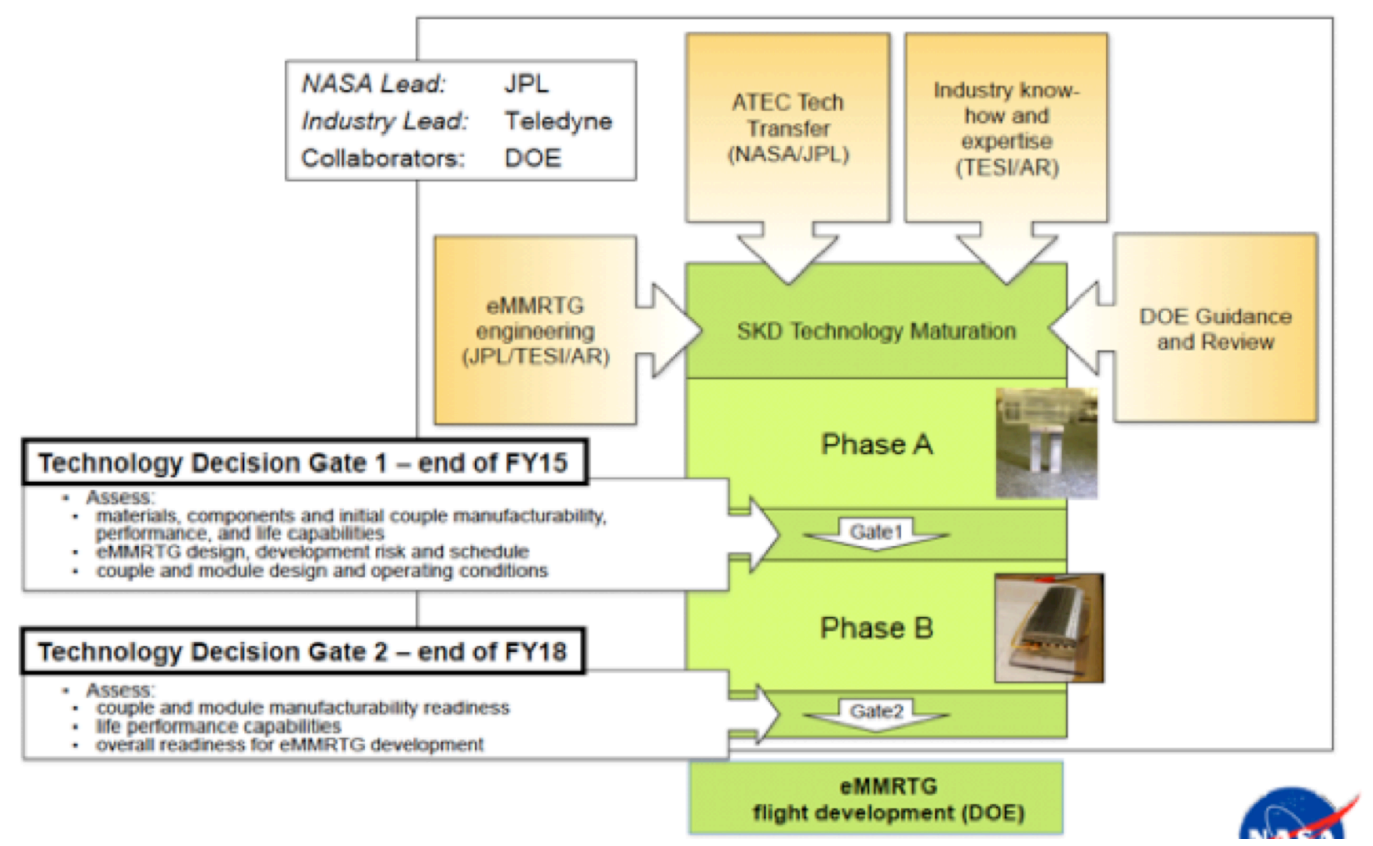

Figure 4. Technology Maturation Model as Currently Utilized for the eMMRTG.

This model is expected to maximize the prospects for successfully evolving the MMRTG into an eMMRTG at a substantially reduced cost and risk. Eventually, TESI should be able to manufacture the devices completely in-house without significant government participation. Installing the couples into the MMRTG with minimum design accommodations should result in a cost savings in qualifying this new generator design. The eMMRTG would provide higher conversion efficiency, leading to greater initial power; however, the greater return on investment would be the reduced degradation over time predicted for the Skutterudite couples. This should result in enhanced end-of-mission power when compared to the MMRTG currently on Curiosity. Such an improvement would be highly significant for mission concepts with long cruise and operational timelines, as is the case for many current RPS-powered missions, since the power system must be sized for end-of-mission power requirements. This performance improvement could potentially result in fewer RTGs being needed to support a given mission concept, saving cost and complexity. 


\section{B. Stirling Cycle Technology Development Project (SCTDP)}

The Nuclear Power Assessment Study (NPAS) and the current Planetary Science Decadal Survey ${ }^{4}$ have affirmed the long-term need for high-efficiency power conversion technology for future planetary missions. Stirling cycle technology, like that of the former ASRG project, would provide a factor of four reduction in plutonium-dioxide fuel needed to produce a given power level when compared to RTGs.

Under the SCTDP, work continues at GRC and Sunpower on Stirling convertor, thermal management and controller tasks. While lagging somewhat behind the TTDP, this effort will eventually follow the same model, with low- and mid-TRL work followed by a technology maturation effort. This organization will emerge following the final close out of the ASRG flight project, which is currently consuming some SCTDP resources. Performance criteria and deliverables are under development. Meanwhile, on-going SCTDP content inherited from the TAP continues. A rough forward-looking plan is shown in Figure 5.

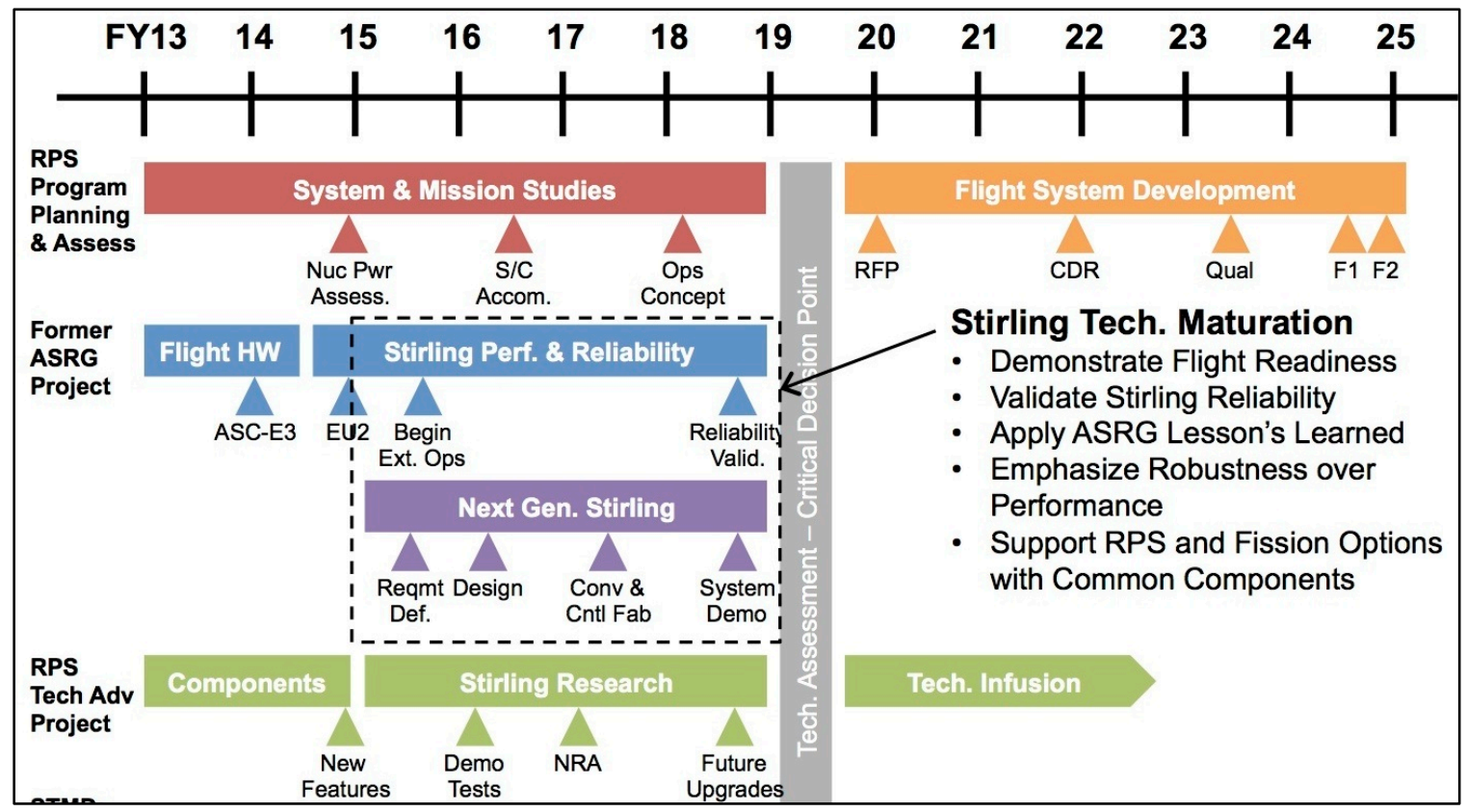

Figure 5. Workflow in the Stirling Cycle Technology Development Project.

The ASRG close-out task will be completed no later than the end of Fiscal Year 2015 (FY15). The flight hardware contract with Lockheed Martin (LM) held by DOE has been terminated and is in its final closeout phase. All work on flight hardware both at LM and Sunpower has been terminated. The RPS

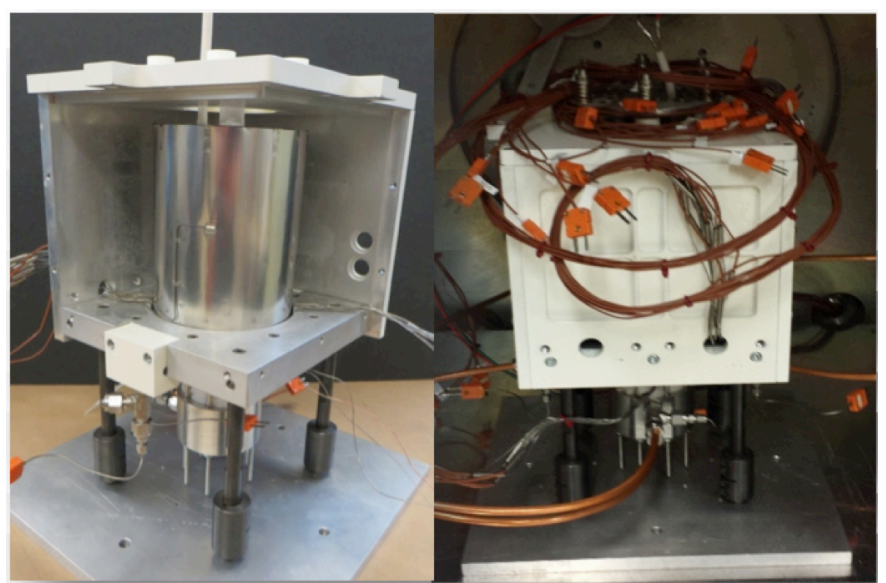

Figure 6. Twenty-five layers of MLI applied and installed into vacuum chamber.
Program has taken possession of all assets associated with the contract and is repurposing or redistributing these in the best interests of the program and other NASA flight projects. Materials that cannot be thus utilized will be excessed.

Low-TRL work currently underway involves generator component-level testing, in materials and subsystems. ${ }^{5,6}$ In the area of improved thermal control, work on multi-layer insulation (MLI) continues toward the goal of reduced mass and improved heat transfer when compared to the state-of-the-art insulation. Preparation for thermalvacuum testing is shown in Figure 6.

Additional component research that could benefit a potential future Stirling 
system is being performed. A Radial Core Heat Spreader (RCHS) is undergoing testing in progressively more fight-like environments. The RCHS uses radial heat pipe technology to improve low temperature heat rejection for the cold side of a Stirling engine. This concept has been validated in the laboratory and has been successfully flight tested on a zero-g aircraft. The next steps include sounding rocket-based tests to verify performance in a longer duration microgravity environment.

The Applied Physics Laboratory developed a Dual Converter Controller (DCC) as a technology demonstration under the TAP. The controller is capable of operating two ASCs as an opposing pair, as was planned for the flight configuration of ASRG and is single-fault tolerant. Work to characterize the dynamic response of the controller and its interaction with ASCs will continue through the end of FY15.

To improve the environmental operational envelope for future systems, tests are characterizing magnets and organic compounds capable of operation at higher ambient temperatures. A deficiency identified in the ASRG was operation in high-albedo environments such as certain Venus flyby trajectories. The higher heat rejection temperatures increase the operating temperatures of the alternator magnets and the organic compounds used in the linear alternator. Margin is required against the Curie temperature of the magnets, and alternative magnets have been identified and are in the qualification process.

The mid-TRL content of the project is focused around the components developed under the ASRG project. ASC-E3s represent the most advanced development of free-piston converters prior to the flight units. An ASC-E3 pair was installed into an aluminum Generator Housing Assembly with flight-like insulation and electric heating elements to simulate General Purpose Heat Source (GPHS) modules. A LM prototype controller based on the flight design was integrated with these components to complete an electrically heated demonstration system. This system, known as EU2, was successfully operated, demonstrating startup, steady-state operation, and limited fault recovery. Following these checkout tests, the system was placed on long-term operation, shown in Figure 7. Power fluctuations in the converters were observed after a relatively short period. The root cause of these is under investigation.

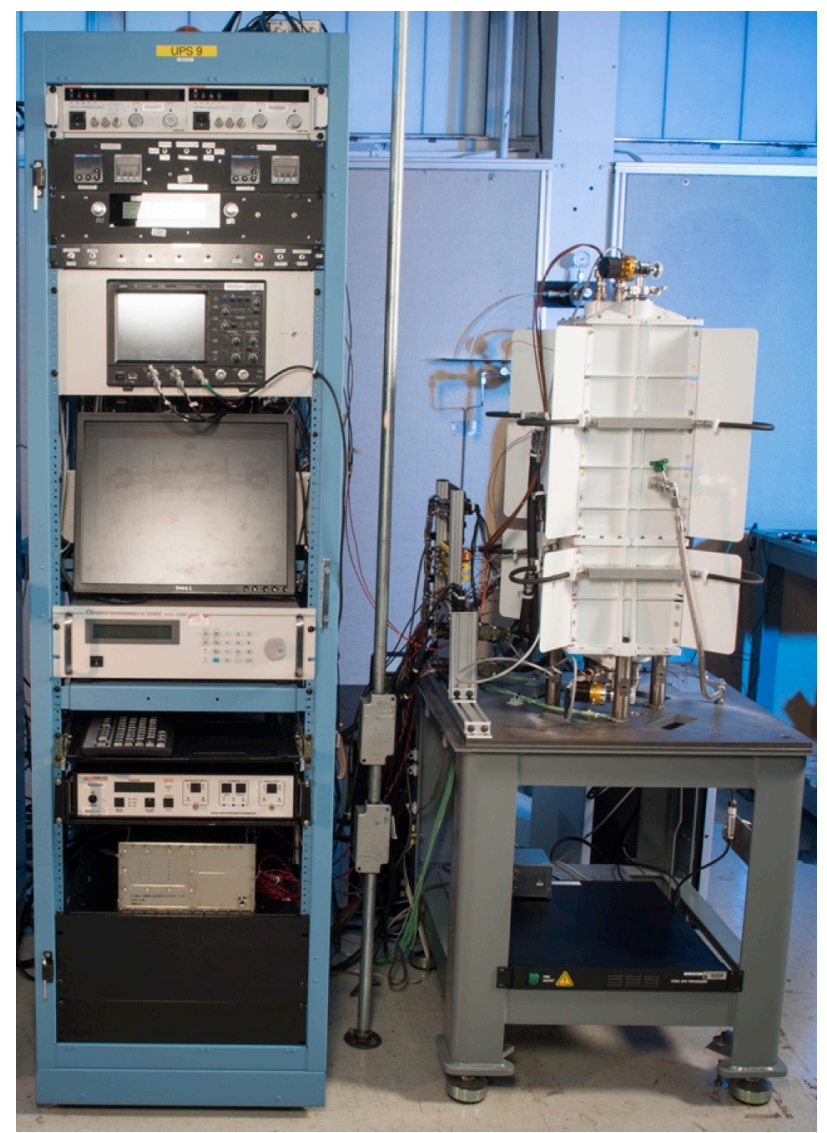

Figure 7. EU2 long-term operations configuration with command and data rack.

The maturation plan for SRG technology is currently under development. Following the cancellation of the ASRG project, PSD made the commitment to continue to invest in SRG technology. The RPS Program will continue to construct ASCs at Sunpower in the near term, but also has begun plans with DOE for a reformulated flight hardware development project.

This plan will begin with a release of a Request for Information to establish whether the industrial base for Stirling converters may be applicable to a flight system. Based on the availability of the converters, Level I and II requirements will be written for a system implementation. Subject to funding availability, this would be followed by a Request for Proposal for a system implementation, beginning with a TM phase. This phase of work would pair the converter with a system integration contractor to develop a full qualification generator system as an end-item deliverable. A contractor/government integrated product team would be formed early to ensure the proper flow of requirements and design information across all project boundaries. The goal of the Stirling development remains to

deploy a highly fuel efficient, robust power system for potential space mission use. 


\section{Nuclear Launch Safety and Launch Approval Engineering}

For any U.S. space mission involving the use of RPS, launch approval must be obtained from the Office of the President. The approval decision is based on an established and proven review process that includes an independent evaluation by an ad hoc Interagency Nuclear Safety Review Panel (INSRP) comprised of representatives from NASA, DOE, the Department of Defense, and the Environmental Protection Agency, with a technical advisor from the Nuclear Regulatory Commission. The Presidential nuclear safety launch approval process requires a detailed safety analysis of the actual system (i.e. power source, spacecraft, launch vehicle, mission design) proposed for launch, resulting in a highly developed model of the space nuclear power application. Since the Presidential nuclear safety launch approval process involves all the federal government agencies that have a substantive safety responsibility for various aspects of the mission, the development and evaluation of the safety analysis provides a focal point for coordinating interagency resolution of any nuclear safety issues identified during the development phase of the application.

DOE uses a launch-vehicle specific databook prepared by NASA to develop a Safety Analysis Report (SAR) for the space mission. The ad hoc INSRP conducts its nuclear safety/risk evaluation, and documents its results in a Safety Evaluation Report (SER). The SER contains an independent evaluation of the proposed mission's radiological risk. DOE uses the SER as its basis for accepting the SAR. If the DOE Secretary formally accepts the SAR-SER package, it is forwarded to the head of the mission-sponsoring agency, e.g., the NASA Administrator, for use in the Presidential launch approval process. The missionsponsoring agency distributes the SAR and SER to the other cognizant government agencies involved in the INSRP, and solicits their opinions of the documents. After receiving responses from these agencies, the agency conducts internal management reviews to address the SAR and SER, and any other nuclear safety information pertinent to the launch. If NASA recommends proceeding with the launch, a formal request for nuclear safety launch approval is sent to the Director of the Office of Science and Technology Policy within the Office of the President; the SAR and SER are included with the request. NASA Headquarters is responsible for implementing this process for NASA missions. DOE supports the process by analyzing the response of power system hardware under different accident scenarios and environments identified in the databook, and prepares a probabilistic risk assessment of the potential radiological consequences and risks to the public and the environment for the launch.

Recent investments made by the RPS Program have helped provide tools that can be used again in future launches, thereby reduce launch preparation time and costs. These Multi-Mission Launch Approval Engineering (MMLAE) investments include:

- Multi-Mission Databooks, reducing mission-specific lead-times and costs for NEPA compliance and development of the SAR databook, and help enable the consideration of using RPS for missions selected through competitive processes

- An Environmental Impact Statement (EIS) template, based on prior RPS mission experience; this template was used to facilitate the development of the Mars 2020 EIS

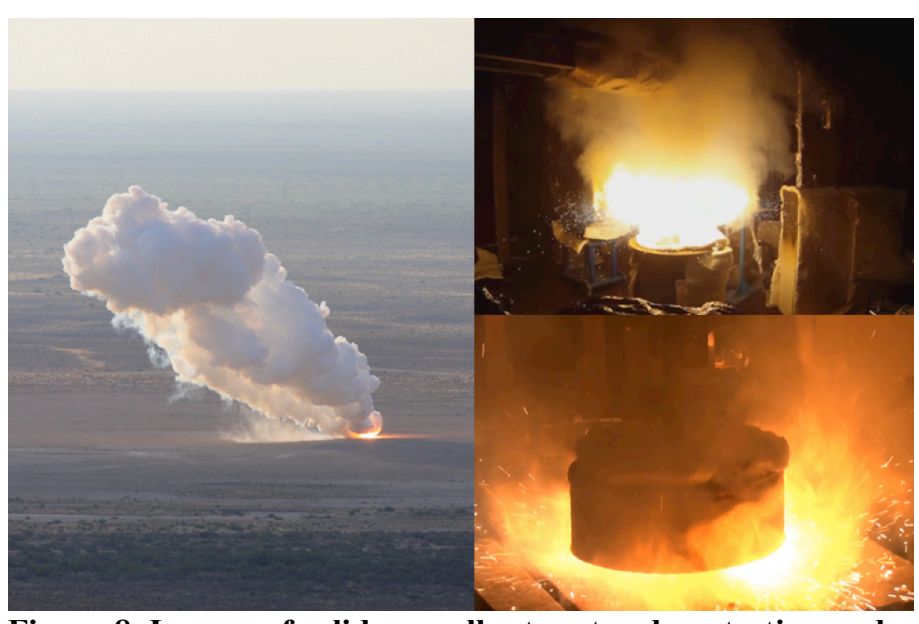

Figure 8. Images of solid propellant motor drop testing and solid propellant fire testing.
- A propellant testing program, which refined/expanded the data set for safety analysis model improvements. The program included tests of burning solid propellant and drop testing of a solid rocket motor, to better characterize the thermal and pressure environments near burning solid propellant (See Figure 8)

- Radiological contingency planning assets that can be used to support future launches. The RPS Program purchased equipment that reduces personnel requirements and associated costs for deployment prior to RPS launch, and would enhance detection capabilities in event of accident. 
Planned work in this area in the coming years includes support for the Mars 2020 RPS launch, scheduled for July 2020, and continued databook development (specifically for the Falcon v1.1 launch vehicle and the Falcon Heavy vehicle). Also planned are real-time RPS re-entry debris field modeling and Mission Flight Control Officer function activities, and analysis of the environments associated with the October 2014 Antares Orb-3 accident. In later years (FY17-18), the team would make improvements to the DSENDS (Dynamic Simulator for Entry, Descent and Surface landing) model, update fragment models, and conduct a large diameter heat shield re-entry analysis.

An interagency effort is underway to develop a set of MMLAE criteria for measuring a RPS mission's progress relative to satisfying mission-specific launch nuclear safety considerations, keyed to project lifecycle review milestones. This would identify all existing nuclear safety/launch approval requirements relevant to each organization, prioritized gaps in those existing requirements, and existing organization activities to fill those gaps and/or to enhance existing requirements.

\section{DOE Capabilities Sustainment}

NASA works in close collaboration with DOE to maintain and improve the systems and capabilities necessary to produce RPS for future NASA missions. Since FY14, NASA has provided funding to DOE for infrastructure funding to maintain RPS capabilities. This method, directed to NASA by the Office of Management and Budget and Congress, seeks to transition to a full cost recovery approach for activities benefitting NASA, yet performed by DOE and their operational laboratories, staff, and other facilities.

\section{A. Plutonium-238 Supply Project}

DOE has initiated a project consistent with a statement of mission need as provided by NASA. This project, known as the Plutonium-238 Supply Project (PSP), makes use of existing facilities at the Oak Ridge National Laboratory (ORNL) and the Idaho National Laboratory (INL) to reestablish the capability to produce $\mathrm{Pu}-238$ at an average rate of at least 1.5 kilograms of plutonium dioxide $\left(\mathrm{PuO}_{2}\right)$ per year. DOE and NASA agreed on this production rate as a means to meet projected mission needs on the shortest schedule and within budget constraints. The PSP was initiated with NASA funding in FY12.

However, due to budget constraints within PSD, the funding for PSP in FY15 and as proposed for FY16 was significantly lower than anticipated. As a result, the project is restructuring and its expected completion date, defined as reaching the $1.5 \mathrm{~kg} /$ year production capability, will likely slip two or more years from its original completion date in 2021. In the interim, the project will be oriented toward providing lower levels of plutonium dioxide production earlier to benefit RPS deployments to specific near-term NASA missions. To date, the four fuel production processes, shown in Figure 9, are proceeding well. Of significance, in the post-irradiation processing arena, the first attempt at co-extraction/partitioning of neptunium from plutonium provided excellent results. The targets for the first of two end-to-end demonstrations have completed irradiation. The first end-to-end chemical recovery demonstration is expected to begin in the summer of 2015 with completion during FY16.

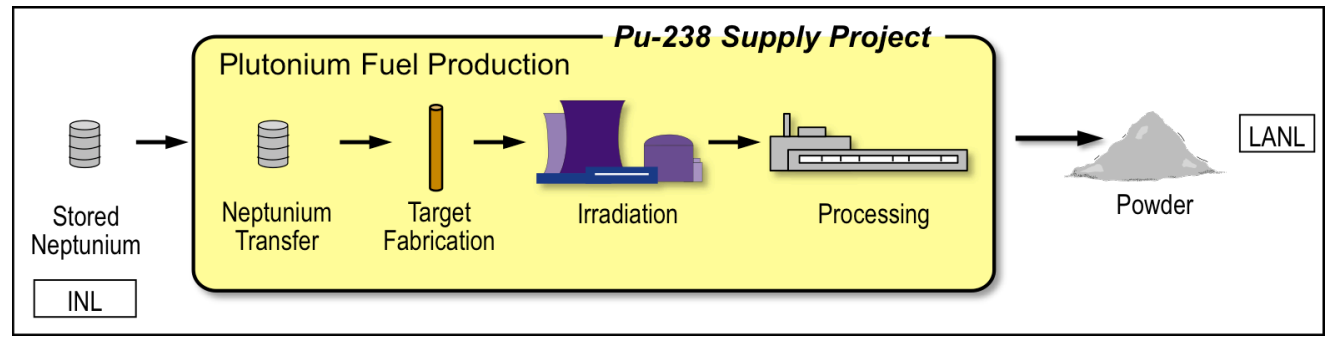

Figure 9. Pu-238 Supply Project Fuel Production.

While NASA has budgeted funding for the cost of reestablishing this national $\mathrm{Pu}-238$ production capability, DOE retains responsibility for operating the national capability if deemed necessary for a range of federal users and for managing efforts related to the safe and secure production of special nuclear material. The cost of sustaining the production capability, once established at completion of this project, would transfer and integrate with the NASA-provided funding of the related DOE RPS Operations and Analysis (O\&A) Program. 


\section{B. DOE Operations and Analysis Program}

The DOE Operations and Analysis Program maintains the personnel skills, mission-supporting capabilities, safety and mission assurance expertise, and physical infrastructure needed to support NASA's future RPS requirements. This sustainment is necessary for continued RPS assembly, testing, and analysis to support potential nuclear-powered missions. These capabilities are dispersed predominantly between four DOE laboratories: INL, ORNL, Los Alamos National Laboratory (LANL), and Sandia National Laboratories (SNL). The laboratories also work closely with one another to achieve mission success.

As previously noted in conjunction with the PSP, any new plutonium dioxide produced is transferred to LANL, and joins the existing fuel inventory there. LANL maintains the capability for fuel processing and fueled clad fabrication. An expanded view of a fueled clad assembly is shown in Figure 10. LANL also specializes in the purification (scrap recovery), pelletization and encapsulation of Pu-238. Additionally, its ability to conduct impact testing, metallography, chemical analysis, nuclear material storage and security, and waste handling and disposal is essential for a mission campaign. The associated facilities are housed in a highly secure area.

INL maintains the capability for RPS assembly, storage, testing, and delivery of RPS for NASA, serves as the Technical Integration Office with respect

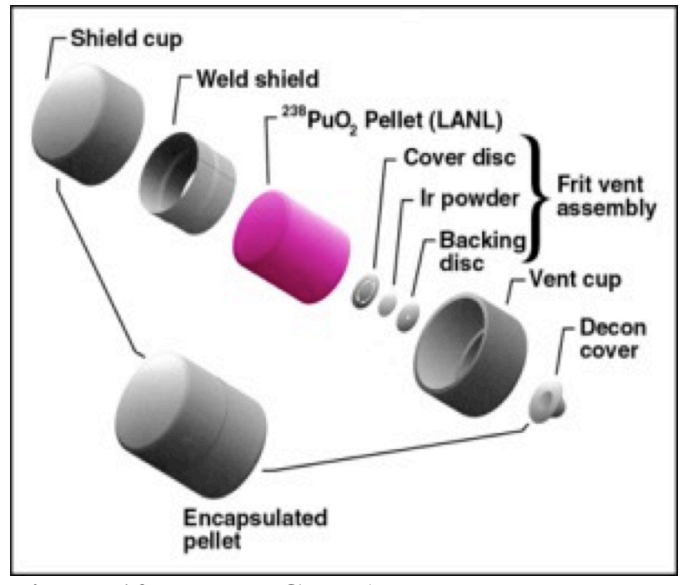

Figure 10. Fueled Clad Assembly. to the other DOE RPS laboratories, and as the Lead Laboratory for quality assurance. Leading up to the assembly of an RPS, INL also develops and procures specialized components/materials, assembles heat source modules, and delivers RPS to the launch site using specialized transportation systems.

ORNL is the lead materials development laboratory for RPS. Their specific capabilities include the manufacture of Carbon-Bonded Carbon Fiber insulation and Light-Weight Radioisotope Heater Unit (LWRHU) components. LWRHU are small devices that are typically used to heat critical components and subsystems for spacecraft. ORNL also produces iridium alloy encapsulation hardware for the fuel clads and maintains unique material testing capabilities.

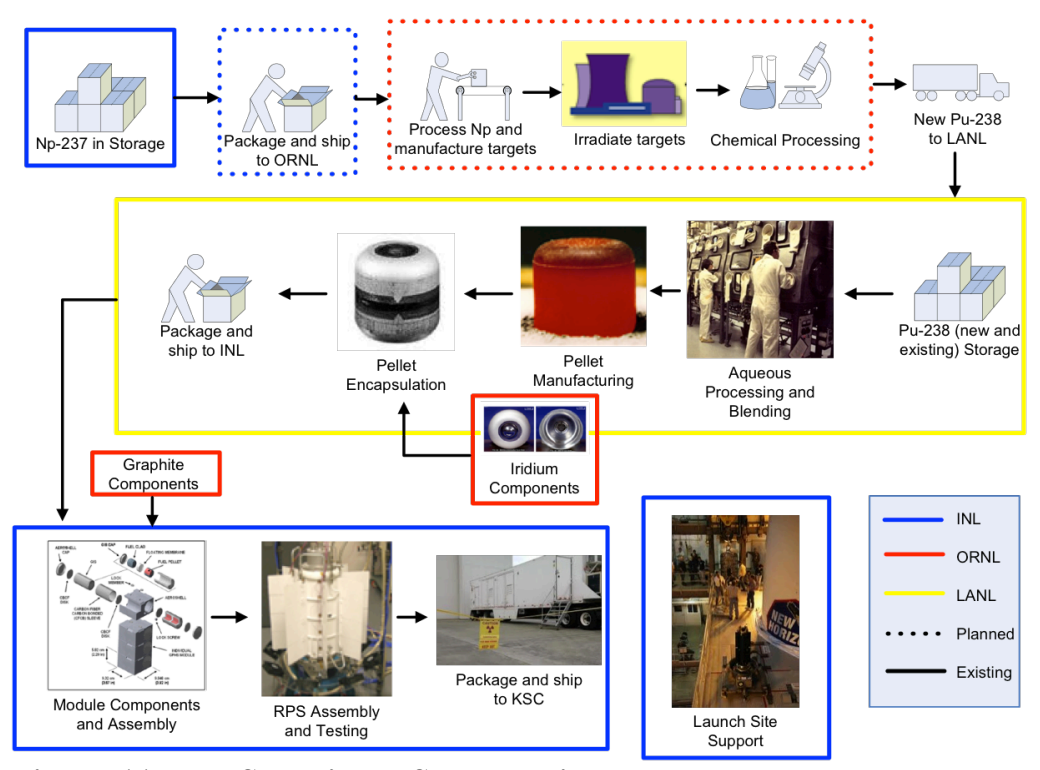

Sandia is the lead lab for safety analysis and safety testing capabilities. SNL maintains critical skills and computational tools to assist in evaluating the safety and performance of RPS on NASA missions. In support of mission-specific EISs that are prepared by NASA, SNL conduct RPS mission risk assessments. In addition, SNL performs nuclear safety analyses, and prepares safety analysis reports to characterize nuclear risks and support mission launch approval.

The keys steps in RPS

Figure 11. Key Steps in RPS Production. production are shown in Figure 11.

Some of the significant O\&A tasks for FY15 include initiating the cold testing of a new hot press and replacing high-priority glovebox windows in Pu-238 laboratories at LANL to provide future redundancy for fueled clad production. Additionally, furnaces are being installed for the preparation of fine-weave pierced fabric (FWPF) components and production of $\mathrm{CBCF}$ insulation at ORNL that are critical to 
producing GPHS modules. At SNL, Mars 2020 launch safely analysis for the upcoming Mars 2020 rover mission is being conducted, and the effects of the recent Antares accident are being investigated to enhance blast- and impact-modeling capabilities.

\section{Mission and Systems Analyses}

The Program Planning and Assessment (PP\&A) Element of the RPS Program is responsible to develop and maintain a comprehensive implementation strategy to meet the stakeholder requirements and expectations of the planetary science community. It is important to ensure the flow of RPS research and technology development is responsive to the needs of potential future NASA science missions by performing mission studies that drive RPS system-level capabilities and mission-imposed requirements and subsequent system studies that drive out generator design requirements. The continuing need for planetary missions has been articulated clearly and repeatedly during the last decade from the National Research Council's 2009 report on RPS ${ }^{7}$ through the 2011 Planetary Science Decadal. ${ }^{4}$ Implementation of nuclear systems for space flight has never been an easy task. Determining investments, including technology investments, to enable these missions and scientific discoveries follows a rigorous process that has been used for decades by NASA. In 2014, on behalf of PSD the PP\&A group initiated the Nuclear Power Assessment Study (NPAS).

Historically, NASA has pursued different approaches for provisioning nuclear power systems. The last Science Mission Directorate (SMD) provisioning study was conducted in 2001 and recommended a dual development activity that would provide both a SRG and a RTG for both deep space and Mars surface missions. The MMRTG, currently powering Curiosity, resulted from this recommendation, as did the technology advancement in Stirling RPS through the ASRG project. Given the cancellation of ASRG project and continued technology investments in Fission Power Systems (FPS) by the NASA Space Technology Mission Directorate, the Nuclear Power Assessment Study (NPAS) was chartered in early 2014 to examine the provisioning approach for future nuclear power systems, for both those that would be radioisotope-and fission-based concepts.

The objective of NPAS was to "Discuss a sustainable strategy and present findings for the provisioning of safe, reliable, and affordable nuclear power systems that enable NASA SMD missions and is extensible to Human Exploration and Operations Mission Directorate (HEOMD) needs in the next 20 years." NASA's PSD sought to understand 1) the potential for commonality between RPS systems for robotic planetary science and the components (and any initial future investments required) in potential fission systems and components, to guide near-term PSD technology investments; 2) the opportunities and challenges of a sustainable, incremental development strategy for nuclear power systems that could be needed to support the efficient development of technology requirements both for SMD needs and future fission capabilities for HEOMD.

NPAS work was performed by the RPS Program in collaboration with NASA centers including GRC, JPL, Goddard Space Flight Center (GSFC), Johnson Space Center (JSC), and Kennedy Space Center (KSC). The DOE and its laboratories, including LANL, INL, SNL, and the Y-12 National Security Complex, also participated. The Johns Hopkins University Applied Physics Laboratory and independent consultants were also contributors. The NPAS was conducted from March through September, 2014.

The NPAS was guided by an Executive Council (EC) and conducted by two primary technical teams: the Mission Study Team (MST) and the Systems Study Team (SST). The two technical teams performed in-depth assessments of mission and systems concepts to address specific considerations provided in the Terms of Reference and answer questions from the EC. The EC was comprised of stakeholders from the relevant NASA mission directorates and flight centers, the DOE, and nuclear safety experts. The EC assimilated reports from the technical teams and developed the findings contained within the final report. Study participants were selected to span a diverse set of experiences to ensure NPAS encompassed a broad view of technology options, mission concepts, and organizational practices.

Nuclear power system performance, technology readiness, cost, and safety as well as operational flexibility, served as the basis for developing the system options and the Design Reference Missions (DRMs). The Design Reference Systems (DRSs) included conceptual, advanced thermoelectrics as well as Stirling converters, which could be utilized in both notional radioisotope and fission system concepts. The technical teams also considered the extensibility of the DRSs to other potential users. The MST evaluated the applicability of the DRSs to smaller NASA Discovery and New Frontiers mission classes. The future 
needs of NASA HEOMD, as stated in its Mars Design Reference Architecture 5.0, were compared to the potential capabilities of the DRS notional concepts.

The MST and SST evaluated mission and systems concepts in the context of the entire system development and mission lifecycles. The MST enumerated options for Assembly, Test, and Launch Operations for both RPS and FPS concepts. The technical teams also assessed nuclear safety, launchapproval processes, and security implications of the notional conceptual systems for the DRMs. The SST prepared notional flight system development plans and examined the impact of fuel availability, infrastructure, and ground-test activities on the notional, proposed system concepts. Both technical teams developed cost estimates for the power system development and implementation on the DRMs. The detailed technical work performed by the MST and SST was provided to the EC for review. The EC distilled the technical data from the teams into the findings and observation that were presented to PSD for consideration. The NPAS team prepared and delivered a detailed final report to PSD with all of the study details, findings and observations.

A key finding of NPAS was that nuclear power systems will continue to be a vital option to enable high-priority SMD mission concepts recommended by the 2011 planetary science decadal survey, and beyond. The power level required for such missions will likely be less than $1 \mathrm{kWe}$ and therefore are best met by radioisotope-based solutions. Sustaining this capability requires plutonium production and funding of the maintenance of the associated DOE infrastructure by NASA. FPS does not represent a good fit for future SMD missions as they are currently envisioned. Due to the size of foreseen FPS concepts, such systems would likely not enable non-orbiting mission (landers and/or rovers), and, would likely not, therefore, enable the breadth and depth of the science goals discussed in the current decadal survey. As with several previous studies, NPAS found that FPS has strong promise - and would likely be requiredfor HEOMD surface missions.

To meet SMD science needs across all mission cost classes, the availability for flight of a combination of both thermoelectric and Stirling converters appear to be most advantageous for the foreseeable future. Advancement of these converter technologies (both static and dynamic) to achieve increased efficiency would have direct benefit to future SMD science missions (including flyby spacecraft, orbiters, landers, and rovers). Continued investments are being pursued to support this advancement and determine the best implementation strategies based on mission-informed system requirements at key decision points in the development. Once successful, these technologies could enable compelling science output by achieving higher power output for longer operational time, balancing plutonium usage and production in support of an increased flight rate. From a NASA perspective, such developments could also help missions remain within budget constraints (via more cost-effective implementations), and help retire mission risk (thanks to more reliable implementations). In any case, it was concluded the outcome resulting from these investments would be of significant benefit to the future space science program.

\section{Conclusion}

Through recent work managed by the RPS Program, ranging from low-TRL technology research through flight system preparations and a long-range forecasting study to determine relevant investments, the future utilization of RPS by NASA SMD remains critical to successful robotic exploration of the solar system. Having recently completed a transition to a NASA funding source, the ongoing support of the DOE capabilities in RPS development and in future production of new plutonium-238 fuel has resulted in a clear path forward in ensuring readiness to support NASA mission needs.

\section{References}

${ }^{1}$ Lewandowski, E., and Oriti, S., "Characterization of the Advanced Stirling Radioisotope Generator EU2, AIAA, July, 2015.

${ }^{2}$ Fleurial, J.P., "A Technology Roadmap for Thermoelectric-Based Next Generation Space Power Systems", to be published in the Journal of Electronic Materials, Special Issue, 2015 International Conference on Thermoelectrics.

${ }^{3}$ Firdosy, S., et al., "Development of High Temperature Device Technologies for the Advanced Thermoelectric Couple Project (ATEC)", Presented at the 2015 Nuclear and Emerging Technologies for Space Conference, Albuquerque, New Mexico, USA, February 2015. 
${ }^{4}$ Committee on the Planetary Science Decadal Survey, National Research Council, "Vision and Voyages for Planetary Science in the Decade 2013-2022," The National Academies Press, Washington, DC, 2011.

${ }^{5}$ Wilson, S., "Overview of Stirling Technology Research at NASA Glenn Research Center", AIAA, July, 2015.

${ }^{6}$ Schwendeman, C., et al, "Optimized Heat Pipe Backup Cooling System Testing with a Stirling Engine", AIAA, July, 2015.

${ }^{7}$ Radioisotope Power Systems Committee, National Research Council, "Radioisotope Power Systems: An Imperative for Maintaining U.S. Leadership in Space Exploration," The National Academies Press, Washington, DC, 2009. 